University of Nebraska - Lincoln

DigitalCommons@University of Nebraska - Lincoln

Faculty Publications: Department of Entomology

2005

\title{
A strategy for using powdered sugar to reduce varroa populations in honey bee colonies
}

Nicholas P. Aliano

University of Nebraska-Lincoln, naliano@unlserve.unl.edu

Marion D. Ellis

University of Nebraska-Lincoln, mellis3@unl.edu

Follow this and additional works at: https://digitalcommons.unl.edu/entomologyfacpub

Part of the Entomology Commons

Aliano, Nicholas P. and Ellis, Marion D., "A strategy for using powdered sugar to reduce varroa populations in honey bee colonies" (2005). Faculty Publications: Department of Entomology. 175.

https://digitalcommons.unl.edu/entomologyfacpub/175

This Article is brought to you for free and open access by the Entomology, Department of at DigitalCommons@University of Nebraska - Lincoln. It has been accepted for inclusion in Faculty Publications: Department of Entomology by an authorized administrator of DigitalCommons@University of Nebraska - Lincoln. 


\title{
A strategy for using powdered sugar to reduce varroa populations in honey bee colonies
}

\author{
Nicholas P Aliano and Marion D Ellis \\ University of Nebraska-Lincoln, Institute of Agriculture and Natural Resources, Department of Entomology, \\ Lincoln, NE 68583, USA
}

Received 9 June 2004, accepted subject to revision 10 November 2004, accepted for publication 8 April 2005

\section{SUMMARY}

We developed a technique to remove varroa (Varroa destructor) from adult honey bees (Apis mellifera) using powdered sugar. Our technique requires isolating a colony's adult bee population in a detachable box prior to powdered sugar application. We designed a detachable 'bee box' that connects to the colony's entrance and is capable of holding the adult bee population. By applying a bee repellent, Bee $\mathrm{Go}^{\circledast}$, to a colony, we forced adult bees into the bee box where they were subsequently dusted with $225 \mathrm{~g}$ of powdered sugar. Adult honey bee populations treated in this manner dropped $76.7 \pm 3.6 \%(n=28)$ of their mites.

Keywords: Apis mellifera, honey bees, Varroa destructor, parasitic mites, control methods, powdered sugar, dust

\section{INTRODUCTION}

Varroa destructor is an obligate ectoparasitic mite of the honey bee, Apis mellifera. Varroa feed on the haemolymph of immature and adult bees during their reproductive and phoretic life stages, respectively. Since the introduction of varroa into the USA in 1987 (American Bee Journal, 1987), the feral population of honey bees has dramatically declined (Harbo \& Hoopingarner, 1997) Managed honey bee colonies have been severely affected as well (Sammataro, 1997; Martin, 2001). Today, varroa is generally considered the most severe threat to beekeeping worldwide.

Chemical resistance, contamination of bee products, and the variable efficacies of current varroa treatments create a need for alternative treatment methods. Fakhimzadeh (2000) evaluated powdered sugar applications to the brood nest as a technique for varroa control. He dislodged mites from adult bees by blowing powdered sugar between the brood frames of colonies. Fakhimzadeh reported that the average mite fall per hour was significantly greater $(P<0.01)$ after applying powdered sugar to 12 colonies. The 12 colonies dropped $0.17 \pm 0.06$ and $5.8 \pm 1.7$ mites per hour before and immediately after powdered sugar application, respectively. Fakhimzadeh's results indicate that dusting colonies with powdered sugar significantly accelerated mite fall.

Macedo et al. (2002) reported using powdered sugar to detect and assess varroa infestations in honey bee colonies. Their method requires collection of approximately 300 adult honey bees in a screened jar. Powdered sugar is then added and the jar gently rolled to distribute the sugar. After sitting for one minute, the jar is inverted and shaken. Macedo et al. achieved $92.9 \pm 5.5 \%$ mite fall when dusting $318 \pm 7$ adult bees in a screened jar with powdered sugar and reported no injury to bees or mites. Our objective was to test the hypothesis that powdered sugar could be used to remove approximately $90 \%$ of mites from adult bee populations when isolated from their nest material based on the findings of Macedo et al. (2002). We predicted that isolation of a colony's adult bee population would ensure even distribution of powdered sugar and eliminate the possibility of mites reattaching themselves to adult bees after dislodgement.

\section{MATERIALS AND METHODS}

\section{Preliminary study}

We conducted our first experiment at the University of Nebraska-Lincoln on 10 October 2002. All 14 experimental colonies were broodless, parasitized with varroa $(0.55 \pm 0.07$ mites per bee), and not fit for wintering. The experimental colonies were allowed to become severely infested with mites for the study and were not maintained beyond the experiment. The outside temperature was $13-15^{\circ} \mathrm{C}$, and few bees were foraging. These conditions enabled us to shake the majority of adult bees from each colony, frame by frame, into a deep hive body via a sheetmetal funnel. The Langstroth deep hive body we used to isolate bees was screened on both open sides with eight-mesh hardware cloth (inside dimensions $=46.7 \mathrm{~cm}$ long, $37.5 \mathrm{~cm}$ wide, and $24.5 \mathrm{~cm}$ deep). One of the screened sides was removable, allowing us to release bees when necessary. After containment, we dusted the bees with $225 \mathrm{~g}$ powdered sugar (Crystal, Minneapolis, MN). We hand-spread the powdered sugar over one of the screened sides, and then brushed the remaining sugar into the box with a bee brush. The boxes were then gently bounced over white butcher paper to recover mites. Bees remained in the cages for five to 10 minutes after dusting and were released near the colony's entrance. Approximately 300 bees were collected in alcohol from each colony both prior to experimentation and directly out of the box after dusting. The mite per bee ratios of the pre- and post-treatment samples were determined using the alcohol wash method (Shimanuki \& Knox, 2000). We also counted the mites collected on butcher paper for each colony.

Approximately one week prior to the study, we shook the adult bee populations from five randomly selected colonies into five separate Langstroth deep hive bodies that were screened on both open sides to establish if box-handling alone would influence mite fall. All five colonies were heavily parasitized with varroa, yet only two mites fell in a 10-minute period. We withheld using controls because we knew box handling without powdered sugar resulted in negligible mite fall. Further, we decided to use all 14 of our experimental colonies as 'treatment' colonies because of limited varroa availability. 
Our experimental design was a random complete block design (RCBD). Hive was the blocking factor, and mite per bee ratio was the response variable. Colony served as both the experimental and sampling unit. We analysed data using PROC MIXED (SAS Institute, 1999) and separated means using a paired $t$ test $(\alpha=0.05)$. We also calculated the percentage mite fall for each of the 14 treatment colonies by comparing pre-treatment and post-treatment mite per bee ratios for each colony. We used the following formula to calculate percentage mite fall:

[1 - (post-treatment infestation / pre-treatment infestation) $] \times$ 100

\section{Secondary study}

We designed and built 10 detachable bee boxes at the University of Nebraska's Agricultural Research and Development Center (ARDC) in August-September, 2003. Our bee boxes were built using pine wood and eight-mesh hardware cloth. The inside dimensions of the boxes measured $46.4 \mathrm{~cm}$ long, $41.3 \mathrm{~cm}$ wide, and $30.5 \mathrm{~cm}$ deep, and they were screened on one $46.4 \mathrm{~cm} \times$ $41.3 \mathrm{~cm}$ side. The inner surface of the box was made of $0.3 \mathrm{~cm}$ melamine composite. The two $41.3 \mathrm{~cm} \times 30.5 \mathrm{~cm}$ sides had the ability to slide open, which enabled us to release bees efficiently. Additionally, both sliding $41.3 \mathrm{~cm} \times 30.5 \mathrm{~cm}$ sides allowed for easy attachment to the entrance of a honey bee colony. The hive entrance and bee box formed a bee-tight seal when connected (fig. 1). A commercial bee repellent (Bee Go) was used to drive the bees into the box. After the bees vacated the colony and entered the box, it was removed, closed, and dusted with 225 $\mathrm{g}$ of powdered sugar. We hand-spread the powdered sugar over the screened side of the bee box, and then brushed the remaining sugar into the box with a bee brush. After dusting, the boxes were gently bounced and agitated to thoroughly coat the bees with powdered sugar. After five minutes, the boxes were inverted and gently bounced over white wax paper to recover mites. Bees remained in the cages for 20-30 minutes after dusting. We used paper towels to seal the hive entrance of each treatment colony during the dusting process. This eliminated the possibility of colonies being robbed while adult bees were absent. Our box was effective in isolating the majority of a colony's adult bees, and was designed to accommodate up to 60000 bees.

We field tested our bee boxes on 28 colonies from three apiaries in October 2003. The three apiaries were designated Pawnee Lake, Denton, and East Campus, and contained 18, 14, and 23 colonies, respectively. All three apiaries were located in Lancaster County, NE, and brood was present in most colonies. Colonies were typical of overwintering bees in Nebraska, and had clusters of bees occupying from nine to 12 frames. We conducted our field trials on the Pawnee Lake, Denton, and East Campus apiaries on the 8,10 and 17 October, respectively. The ambient air temperatures at the beginning of our field trials on these days were $31.7,29.9$ and $16.8^{\circ} \mathrm{C}$, respectively. We randomly designated half of the colonies for treatment and half as controls for each apiary (East Campus was an exception, as it had 11 control and 12 treatment colonies). We collected approximately 300 bees in alcohol from brood combs for both treatment and control colonies prior to experimentation. After pre-treatment alcohol samples were collected, we attached a bee box to each of the treatment colonies. We then applied Bee Go to treatment colonies, and proceeded to dust them with powdered sugar in the manner previously described. After dusting the bees and allowing them to groom themselves for 20 to 30 minutes, we took a second alcohol sample of approximately 300 bees directly from the box and collected fallen mites from the butcher paper. Finally, we sprayed the bees lightly with water to reduce flying and shook them into an empty deep hive body placed over the second brood box (fig. 2). We then covered the empty hive body with a screen to provide adequate ventilation. The empty hive body was removed after the bees reoccupied their nest material, and the inner cover and lid were replaced. Two days later, we took our final alcohol samples of approximately 300 bees from both treatment and control colonies, and

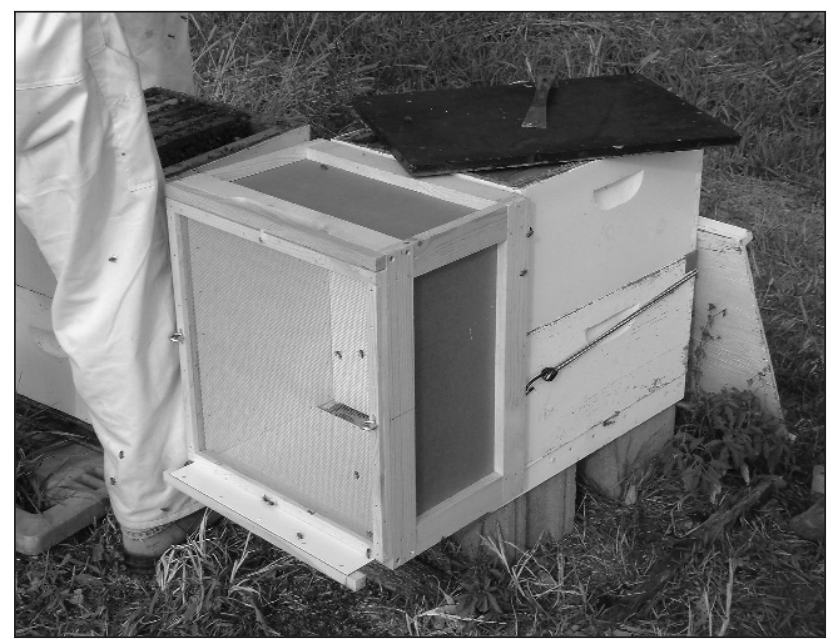

FIG. 1. Solid bottom bee-box attached to a colony prior to isolation of the adult bee population.

the mite per bee ratios were determined using the alcohol wash method.

We performed the same box-handling technique (described above for the preliminary study) on five more varroa-infested colonies to establish if box-handling alone would influence mite fall. Approximately one week prior to the second study, we isolated five adult bee populations from their nest material using Bee Go and our detachable bee boxes. Again, we only recovered a very small number of mites (3) after 15 to 20 minutes in our boxes. We withheld isolating control colonies in our bee boxes because we knew box-handling without powdered sugar resulted in negligible mite fall. Further, we only built 10 detachable bee boxes for use in the second study. For this reason, it was impossible to attach boxes to both treatment and control colonies in the same apiary. In summary, the control colonies in the second study were not handled other than collecting adult bee samples in alcohol.

We used a repeated measures experimental design model to analyse the combined mite per bee ratio data of all three apiaries. We considered three factors: (1) apiary location (Pawnee Lake, Denton, and East Campus), (2) treatment (powdered sugar and no powdered sugar), and (3) alcohol collection time (pretreatment and 2 days post-treatment). Each hive was considered a block, thus the subject effect was [hive (location*treatment)]. The experimental and sampling units were both the colony. We used an unstructured covariance model and the KenwoodRogers degrees of freedom adjustment. We analysed data using

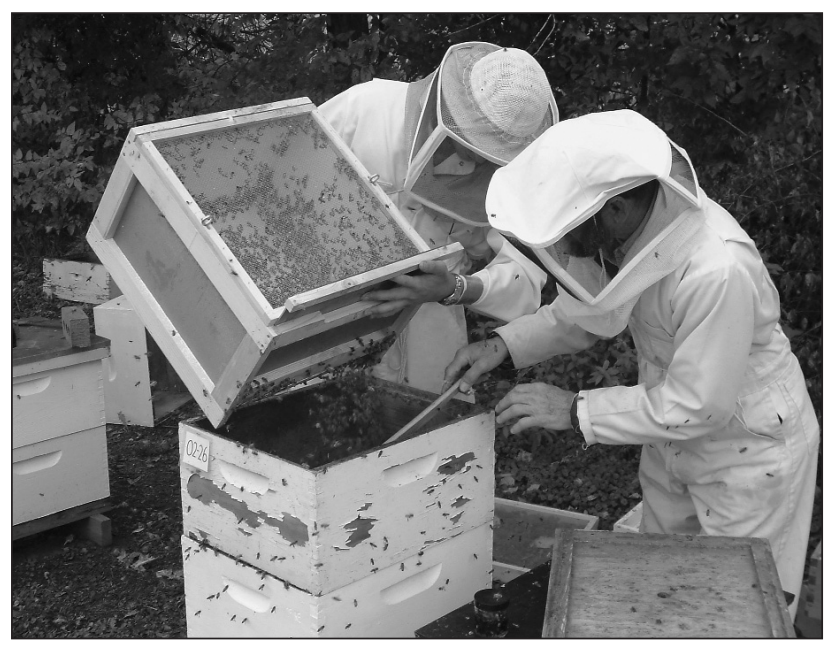

FIG. 2. Returning bees to their colony after dusting with powdered sugar. 


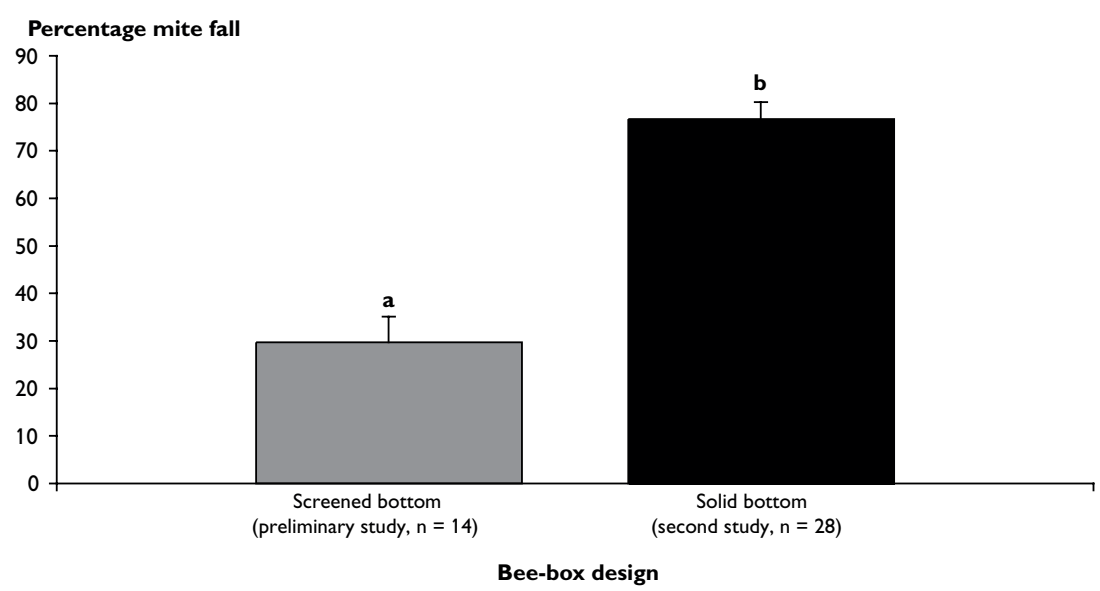

FIG. 3. Percentage mite fall for two box designs used to treat adult honey bee populations for varroa with powdered sugar. Treatments bearing different letters were significantly different ( $t$ test, $\alpha=0.05$ ).

PROC MIXED (SAS Institute, 1999) and separated means using a paired $t$ test $(\alpha=0.05)$. We also calculated the percentage mite fall for the 28 treatment colonies by comparing pre-treatment alcohol samples with those taken directly from the bee boxes after dusting.

We attached a thermometer to the screened top of three bee box treatments in the East Campus apiary. We recorded the bee box temperature 5, 10,15, 20, 25 and 30 minutes after bees were dusted. We used a random complete block design (RCBD) to analyse our data. Hive was the blocking factor and temperature $\left({ }^{\circ} \mathrm{C}\right)$ was the response variable. The experimental and sampling units were both the colony. We analysed temperature data using PROC MIXED (SAS Institute, 1999) and separated means using a paired $t$ test $(\alpha=0.05)$.

\section{RESULTS}

\section{Preliminary study}

The 14 adult bee populations dusted with powdered sugar on 10 October 2002 had an average pre-treatment mite per bee ratio of $0.55 \pm 0.07$. The average post-treatment mite per bee ratio was $0.37 \pm 0.07$. The treatment effect was significant $(F=$ $12.1 ; \mathrm{df}=1,13 ; P=0.0041$ ), as mite numbers declined following treatment. There was a difference of $0.18 \pm 0.05$ mites per bee between the pre and post-treatment samples $(t=3.48$; $d f=13$; $P=0.0041)$.

The average percentage mite fall for the 14 colonies was $29.7 \pm$ 5.4 (fig. 3). The average number of mites collected (on butcher paper along with powdered sugar) from each colony after dusting was $325.2 \pm 58.5$.

\section{Secondary study}

There was significant treatment by time interaction $(F=9.1$; df $=1,53 ; P=0.0039$ ), and therefore, we are reporting simple effects for these two factors. The five treatment means for the effect treatment*time are shown in table 1 . We considered the main effect of location because it was not part of the interaction. There was no location effect $(F=2.35 ; \mathrm{df}=2,51 ; P=$ 0.1055).

There were no significant differences in the mite per bee ratios between treatment and control colonies prior to experimentation for all three apiaries combined $(t=0.4 ; \mathrm{df}=50.7 ; P=$ 0.6887).

In the control colonies, the pre-treatment alcohol samples had $0.06 \pm 0.02$ fewer mites per bee than samples taken two days post-treatment $(t=2.3 ; \mathrm{df}=53 ; P=0.0257)$. In contrast, in the treatment colonies, the pre-treatment alcohol samples had 0.05 \pm 0.02 more mites per bee than samples taken two days posttreatment $(t=1.97 ; \mathrm{df}=53 ; P=0.05)$. When only considering the alcohol samples taken two days post-treatment, the control colonies had $0.09 \pm 0.05$ more mites per bee than the treatment colonies $(t=2.06 ; \mathrm{df}=50.7 ; P=0.0447)$ (table 1).

There were no significant differences in bee box temperatures between the 5,10,15, 20, 25 and 30 minute sampling times $(F$ $=2.81 ; \mathrm{df}=5,10 ; P=0.0772$ ). The average periphery temperature of the bee boxes over a 30 minute interval was $32.5^{\circ} \mathrm{C} \pm$ $0.6(n=18)$. Bees began to regurgitate honey when the temperature reached $35^{\circ} \mathrm{C}$. We promptly released the bees if the bee box reached $35^{\circ} \mathrm{C}$ to prevent further stress.

The average percentage mite fall for the 28 colonies was $76.7 \pm$ $3.6 \%$ (fig. 3). The average number of mites collected from each colony after dusting was $841.7 \pm 94.6$. The average number of mites collected on butcher paper among the three apiaries was not significantly different $(F=0.78 ; \mathrm{df}=2,25 ; P=0.4678)$.

\section{Preliminary and secondary studies combined}

The average pre-treatment mite per bee ratio of treatment colonies was greater in our preliminary study $(0.43 \pm 0.06)$ than in our secondary study $(t=6.89 ; \mathrm{df}=40 ; P=0.0001)$.

Mite fall increased by $47.0 \pm 6.4 \%$ in our secondary study compared to our preliminary study $(t=7.34 ; \mathrm{df}=40 ; P=0.0001)$. Similarly, we recovered more mites after dusting $(516.5 \pm 140.6)$ in our secondary study $(t=3.67 ; \mathrm{df}=40 ; P=0.0007)$.

\section{DISCUSSION}

The data from our preliminary experiment indicate that $29.7 \pm$ $5.4 \%$ of the varroa on adult bees are removed when bees are dusted with powdered sugar in a box with a screened bottom and top. We increased percentage mite fall to $76.7 \pm 3.6 \%$ in our secondary study by adding solid bottoms to our bee boxes. We did not succeed in removing $90 \%$ of the mites from adult bees isolated from their nest material as reported by Macedo et al. (2002). One reason we did not achieve $90 \%$ mite fall may be attributed to not using screened bottom boards to monitor mite fall after returning bees to their colonies following treatment. For this reason, the $76.7 \%$ mite removal may be an underestimate because mites continue to fall for several hours after dusting adult bees with powdered sugar (personal observation). However, the $76.7 \%$ mite removal represents a level of control that is comparable to other treatments used to reduce mite populations. 
We believe that the bee boxes used in the second study were more effective at knocking off mites from adult bees because they had a solid bottom, thus ensuring even distribution of powdered sugar on adult bees. Additionally, our solid bottom bee boxes retained heat, which may have contributed to mite drop. Three of our treatment colonies in the Pawnee Lake apiary had $100 \%$ mite fall, but these colonies also regurgitated honey due to temperature stress. Subsequent treatment colonies were checked periodically during their 20-30-minute period in the bee box to prevent heat stress. In contrast, the boxes used in our preliminary study had screened bottoms, which allowed much of the powdered sugar to pass through without sticking to the bees. We noticed that bees dusted in boxes with screened bottoms were not as evenly covered with powdered sugar as those in our solid-bottom bee boxes. The screened bottom also allowed more ventilation, and such boxes could be left inverted for over an hour without reaching temperatures high enough to cause regurgitation. Our results suggest that higher temperatures may increase mite fall when bees are isolated from their nest material and dusted with powdered sugar.

The average pre-treatment mite per bee ratio of treatment colonies was $0.43 \pm 0.06$ mites per bee greater in our preliminary study than in our secondary study. Although initial varroa infestation was higher in the preliminary study, mite fall was 47.0 $\pm 6.4 \%$ greater in our secondary study. Similarly, we recovered $516.5 \pm 140.6$ more mites per colony after dusting adult bees in our secondary study. Again, these results indicate that powdered sugar is more effective at knocking mites off adult bees when administered in a solid bottomed container.

The colonies used in the preliminary study were allowed to become severely infested with mites and were not maintained beyond the experiment. In contrast, colonies used in the second study were typical of overwintering bees in Nebraska, and had clusters of bees occupying from nine to 12 frames. As a result, the colonies in the preliminary study had smaller adult bee populations than colonies in the second study. Aliano \& Ellis (unpublished) tested the effects of bee density on mite fall when dusting caged bees with powdered sugar in a controlled environment. The results indicated that bee density is independent of mite fall when dusting bees in a well-ventilated screened cage and that mite fall increased at higher bee densities in cages with solid bottoms. Consequently, we are confident that our comparisons of screened and solid-bottomed boxes are valid despite the variable bee densities of experimental colonies.

Most of the colonies in our secondary study had brood present. Varroa emerging with young adult bees explains why mite infestation increased by $0.06 \pm 0.02$ mites per bee in control colonies after two days. In contrast, colonies treated with powdered sugar had $0.05 \pm 0.02$ fewer mites per bee two days after treatment (table 1). Although our treatment method significantly reduced mite infestation two days after applying powdered sugar, we believe it is best to dust adult bees when the colony is broodless. The broodless condition eliminates the possibility of varroa emerging with young adult bees and maximizes the efficiency of our technique.

One drawback of our technique is that it is labour intensive and time consuming. We (two people) were able to treat seven to nine colonies in a three hour period. This is longer than it would take a normal beekeeper because we were also collecting alcohol samples, monitoring fallen mites and taking notes. Regardless, our technique is not feasible for commercial beekeepers due to time limitations. Smaller scale beekeepers may readily adopt this technique, especially those trying to reduce the use of chemical treatments. Finally, our technique may be useful to scientists who wish to recover large numbers of mites for experimental purposes (we collected 2271 mites from one colony). This is much easier than removing varroa from capped brood cells one at a time. The mites we recovered were lively and seemingly unharmed. We do not know if varroa removed using our technique are able to resume their phoretic period and
TABLE I. Solid bottom bee-box mite per bee treatment means for the effect treatment*time (second study).

\begin{tabular}{ll}
\hline Treatment & Estimate \pm standard error \\
\hline control-pre & $0.12 \pm 0.02(n=27) \mathrm{a}^{*}$ \\
control-2day post & $0.17 \pm 0.03(n=27) \mathrm{b}$ \\
treatment-pre & $0.13 \pm 0.02(n=28) \mathrm{ab}$ \\
treatment-box & $0.02 \pm 0.01(n=28) \mathrm{c}$ \\
treatment-2day post & $0.08 \pm 0.03(n=28) \mathrm{d}$ \\
*Treatments bearing different letters were significantly different $(t$ test, $\alpha=0.05)$
\end{tabular}

reproduce if introduced back into a colony or cohort of adult bees.

\section{Acknowledgements}

Funding for this research was provided by an EPA regional PESP grant. Additional funding was provided by the Nebraska Honey Producers and the Wisconsin Beekeepers Association. We thank Dr Erin Blankenship for her advice on experimental design and data analysis. We thank Bill McCormick for his help in constructing and testing our bee boxes. Finally, we thank Bob Roselle for spending countless hours counting varroa and honey bees. This is paper number 14625 of the journal series of the Agricultural Research Division, University of Nebraska-Lincoln.

\section{REFERENCES}

AMERICAN BEE JOURNAL (1987) Varroa mites found in the United States. American Bee Journal 127(11): 745-746.

FAKHIMZADEH, K (2000) Potential of super-fine ground, plain white sugar dusting as an ecological tool for the control of Varroasis in the honey bee (Apis mellifera). American Bee Journal 140(6): 487-490.

HARBO, J R; HOOPINGARNER, R A (1997) Honey bees (Hymenoptera: Apidae) in the United States that express resistance to Varroa jacobsoni (Mesostigmata: Varroidae). Journal of Economic Entomology 90(4): 893-898.

MACEDO, P A; WU, J; ELLIS, M D (2002) Using inert dusts to detect and assess varroa infestations in honey bee colonies. Journal of Apicultural Research 40(1-2): $3-7$.

MARTIN, S J (2001) The role of Varroa and viral pathogens in the collapse of honey bee colonies: a modeling approach. Journal of Applied Ecology 38: 1082-1093.

SAMMATARO, D (1997) Report on parasitic honey bee mites and disease associations. American Bee Journal 137(4): 301-302.

SAS INSTITUTE (1999) SAS/STAT user's guide, version 8.0. SAS Institute; Cary, NC, USA.

SHIMANUKI, H; KNOX, D A (2000) Diagnosis of honey bee diseases. Agricultural Handbook No. AH-690; US Department of Agriculture; Beltsville, MD, USA; 53 Pp. 